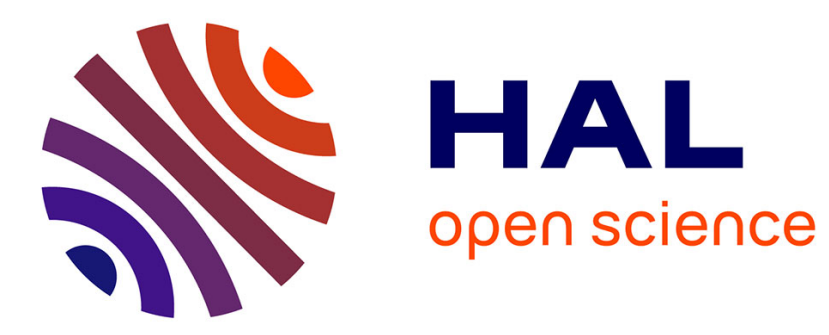

\title{
Properties of Surface Layers Produced from a Metalorganic Titanium Compound Under Glow Discharge Conditions
}

T. Wierzchon, J. Sobiecki

\section{- To cite this version:}

T. Wierzchon, J. Sobiecki. Properties of Surface Layers Produced from a Metalorganic Titanium Compound Under Glow Discharge Conditions. Journal de Physique IV Proceedings, 1995, 05 (C5), pp.C5-699-C5-703. 10.1051/jphyscol:1995584 • jpa-00253946

\section{HAL Id: jpa-00253946 https://hal.science/jpa-00253946}

Submitted on 1 Jan 1995

HAL is a multi-disciplinary open access archive for the deposit and dissemination of scientific research documents, whether they are published or not. The documents may come from teaching and research institutions in France or abroad, or from public or private research centers.
L'archive ouverte pluridisciplinaire HAL, est destinée au dépôt et à la diffusion de documents scientifiques de niveau recherche, publiés ou non, émanant des établissements d'enseignement et de recherche français ou étrangers, des laboratoires publics ou privés. 


\title{
Properties of Surface Layers Produced from a Metalorganic Titanium Compound Under Glow Discharge Conditions
}

\author{
T. Wierzchof and J.R. Sobiecki \\ Department of Materials Science and Engineering, Warsaw University of Technology, 02-524 Warsaw, \\ Narbutta 85, Poland
}

\begin{abstract}
A prospective line in the development of thermo-chemical treatments under glow discharge conditions is to work out new techniques of producing multicomponent layers, e.g., composite layers, by combining various treatments, such as e.g. plasma nitriding and the PACVD method. The combined properties, appropriately selected and complementary to one another, of the single-component layers obtained using one of these processes, permit widening the application range of the layers. The paper specifies the conditions under which the multicomponent layers of $\mathrm{Ti}(\mathrm{OCN})$ type and composite layers of the nitrided + TiN or nitrided $+\mathrm{Ti}(\mathrm{OCN})$ type can be produced on steel. The structure and properties of the layers thus obtained are also described.
\end{abstract}

\section{INTRODUCTION}

The prospects of the further development of surface engeneering lie in new low-temperature CVD techniques for the deposition of hard surface layers, such as e.g. the glow discharge assisted- or pulse plasma CVD methods [1-3]. In the CVD technique carried out under glow discharge conditions (the PACVD process), the gaseous medium is activated not only thermally (apparatus with the hot-anode [3]), but also electrically. This permits a considerable reduction of the deposition temperature. In the present work, $\mathrm{TiCl}_{4}$, commonly used for producing $\mathrm{TiC}$, $\mathrm{TiN}, \mathrm{Ti}(\mathrm{CN})$ layers by CVD processes, was replaced by a mixture that contained tetraisopropoxytitanium vapours $\mathrm{Ti}\left(\mathrm{OiC}_{3} \mathrm{H}_{7}\right)_{4}$, hydrogen and nitrogen. Because titanium, oxygen and carbon are present in the $\mathrm{Ti}\left(\mathrm{OiC}_{3} \mathrm{H}_{7}\right)_{4}$ compound, the layer produced contains these elements and in addition nitrogen from the gas mixture $[2,4]$. The layer may be described as $\mathrm{Ti}(\mathrm{OCN})$. Such layers, showing a good resistance to wear, have already been obtained using the gaseous atmosphere composed of $\mathrm{TiCl}_{4}$, $\mathrm{N}_{2}, \mathrm{CH}_{4}$ and $\mathrm{CO}_{2}[5]$.

\section{EXPERIMENTAL METHODS}

The multicomponent layers of the Ti(OCN) type and composite layers built of a nitrided layer covered with a $\mathrm{Ti}(\mathrm{OCN})$ or TiN layer were produced in a universal apparatus designed for glow discharge assisted thermo-chemical treatments. The apparatus permits plasma diffusion processes (e.g., nitriding, carbonitriding, boriding) and PACVD processes to be carried out in various gaseous atmospheres. It also enables the composition of the gaseous mixture to be modified during the process [3]. A schematic diagram of the apparatus is shown in Fig. 1. 


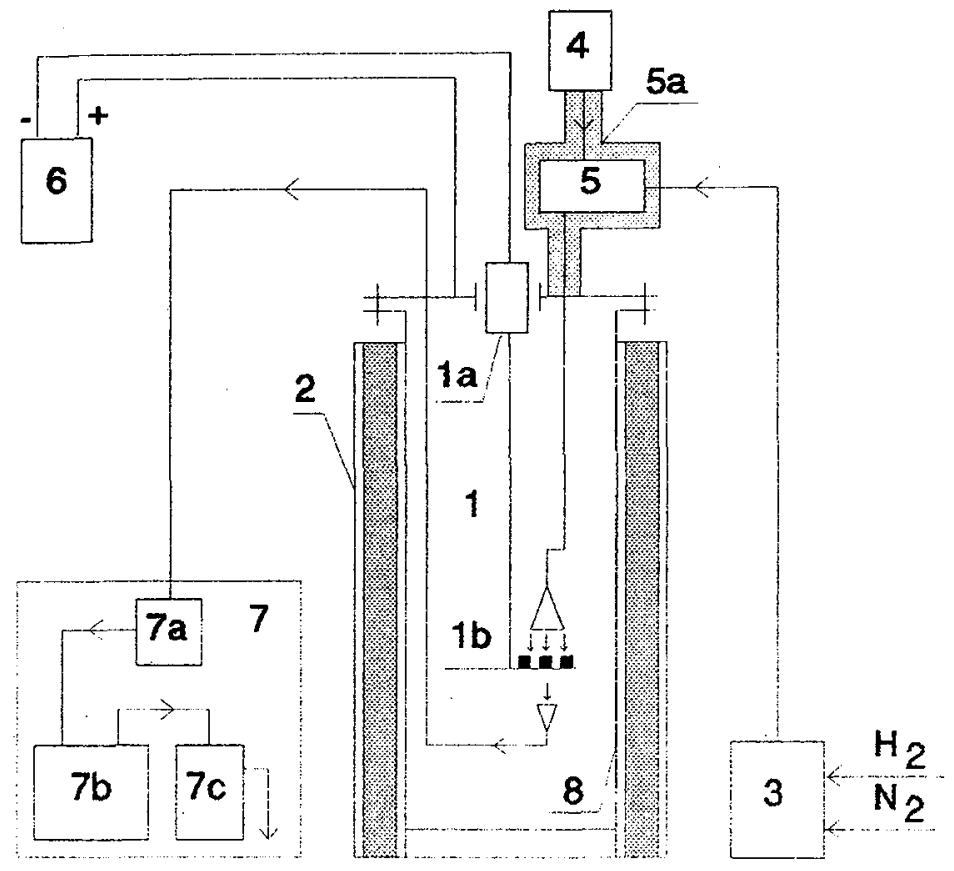

Figure 1. Schematic diagram of the apparatus for thermo-chemical treatments carried out under glow discharge conditions: 1- reaction chamber with an electric bushing (1a) and a treated part holder ( $1 \mathrm{~b}$ - the cathode), 2 - resistance furnace, 3 - dosing device, $4-\mathrm{Ti}\left(\mathrm{OiC}_{3} \mathrm{H}_{7}\right)_{4}$ or $\mathrm{TiCl}_{4}$ dosing device, $5-\mathrm{Ti}\left(\mathrm{OiC}_{3} \mathrm{H}_{7}\right)_{4}$ vapours $+\mathrm{H}_{2}+\mathrm{N}_{2}$ mixer $(5 \mathrm{a}-$ thermostat), 6 - dc voltage supply unit, 7 - vacuum system (7a - cooling trap, $7 b$ - vacuum pump, $7 \mathrm{c}$ - ail absorber of gases), 8 - reaction chamber (the anode).

The composite layers were produced by the so-called single stage processes, in which after the plasma nitriding in the $\mathrm{N}_{2}+\mathrm{H}_{2}$ atmosphere, $\mathrm{TiCl}_{4}$ or $\mathrm{Ti}\left(\mathrm{OiC}_{3} \mathrm{H}_{7}\right)_{4}$ vapours mixed with $\mathrm{N}_{2}+\mathrm{H}_{2}$ were introduced into the reaction chamber and, by changing the current-voltage parameters, TiN or Ti(OCN) layers are produced. The nitriding process lasted 3 hours and after that, a multicomponent layer was obtained using a voltage of $1100 \mathrm{~V}$, a total pressure of $5 \mathrm{hPa}$., a coating time of 2 hours. The optimum temperature for producing $\mathrm{Ti}(\mathrm{OCN})$ layers was $500^{\circ} \mathrm{C}[6]$. The multicomponent and composite layers were formed on Armco iron $(0.05 \% \mathrm{C}), 1 \mathrm{H} 18 \mathrm{~N} 9 \mathrm{~T}$ steel $(0.1 \% \mathrm{C}, 18 \% \mathrm{Cr}, 9 \% \mathrm{Ni}$, $0.5 \% \mathrm{Ti})$ and SW7M steel $(0.88 \% \mathrm{C}, 4.3 \% \mathrm{Cr}, 5 \% \mathrm{Mo}, 6.5 \% \mathrm{~W}, 1.95 \% \mathrm{~V})$. The stainless steel of the $1 \mathrm{H} 18 \mathrm{~N} 9 \mathrm{~T}$ type was nitrided under glow discharge conditions at a temperature of $760^{\circ} \mathrm{C}$ and then TiN layers were produced at $650^{\circ} \mathrm{C}$ or $\mathrm{Ti}(\mathrm{OCN})$ layers at $500^{\circ} \mathrm{C}$. The content of $\mathrm{TiCl}_{4}$ or $\mathrm{Ti}\left(\mathrm{OiC}_{3} \mathrm{H}_{7}\right)_{4}$ vapours in the gas atmosphere was about $10 \%$ (by volume). The metallographic microsections were etched either with nital (SW7M steel and Armco iron) or with an etchant based on $\mathrm{HNO}_{3}, \mathrm{HF}$ and $\mathrm{H}_{2} \mathrm{O}$ (1H18N9T steel specimens). The resistance to corrosion of the layers were examined by the potentiodynamic method. The measurements were made in a $0.5 \mathrm{M} \mathrm{NaCl}$ aqueous solution at a temperature of $25^{\circ} \mathrm{C}$. The reference electrode was a saturated calomel electrode. The electric potential was varied at a rate of $1000 \mathrm{mV} / \mathrm{h}$. The potentiostate used was a Taccusel PRT-20 $[3,4]$. The resistance to frictional wear was examined using the "three rollers + taper" method under the following conditions: the unit load $-200,400 \mathrm{MPa}$, the friction rate $-0.58 \mathrm{~m} / \mathrm{s}$, the lubricant medium - the Lux 10 lubricant, drip-fed at a rate of $30 \mathrm{drops} / \mathrm{min}$, the wear depth - measured microscopically, the frictional load - increased at $10 \mathrm{~min}$ intervals [7]. In this test friction is applied between three $8 \mathrm{~mm}$-diam. cylindrical specimens (rollers) and a rotating conical counterspecimen (a taper). The linear wear, expressed as the wear depth was determined by measuring the diameters of the ellipses formed on the surface layer of the individual rollers. The counterspecimen was made of AISI45 steel, quench hardened and tempered to a hardness of 30HRC. The test time was 100 min, but it was interrupted at intervals of $10 \mathrm{~min}$ at which the worn area (elliptical in shape) was measured. After each interruption the load was increased so as to maintain a constant unit load. 


\section{RESULTS}

Fig. 2 shows an example of microstructures of the Ti(OCN) layers and of the composite layers of the two types: nitrided + TiN and nitrided $+\mathrm{Ti}(\mathrm{OCN})$, formed on various steels. The TiN or Ti(OCN) layers were up to $10 \mu \mathrm{m}$ thick and their surface hardness was in the range from 1500 to $2150 \mathrm{HV} 0.05$.
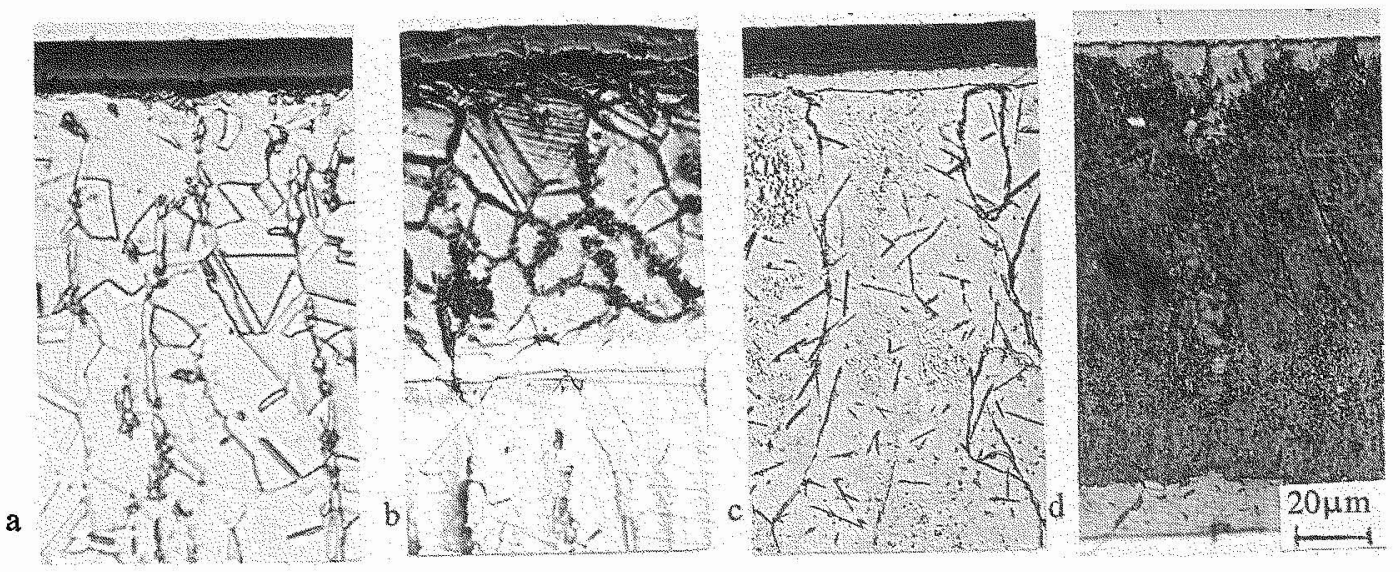

Figure 2. Microstructures of a multicomponent and composite surface layers formed on various steel grades: a) Ti(OCN) on $1 \mathrm{H} 18 \mathrm{~N} 9 \mathrm{~T}$ steel, b) composite nitrided + Ti(OCN) layers formed on $1 \mathrm{H} 18 \mathrm{~N} 9 \mathrm{~T}$ steel c) Ti(OCN) on Armco iron and d) composite nitrided + TiN layer on $1 \mathrm{H} 18 \mathrm{~N} 9 \mathrm{~T}$ steel.

Fig. 3a,b compare the potentiodynamic curves representing the corrosion resistances of Ti(OCN) and of composite layers (both the nitrided + TiN and nitrided + Ti(OCN) types) with the curves representing the corrosion resistances of the substrate material and of a nitrided layer.

a)

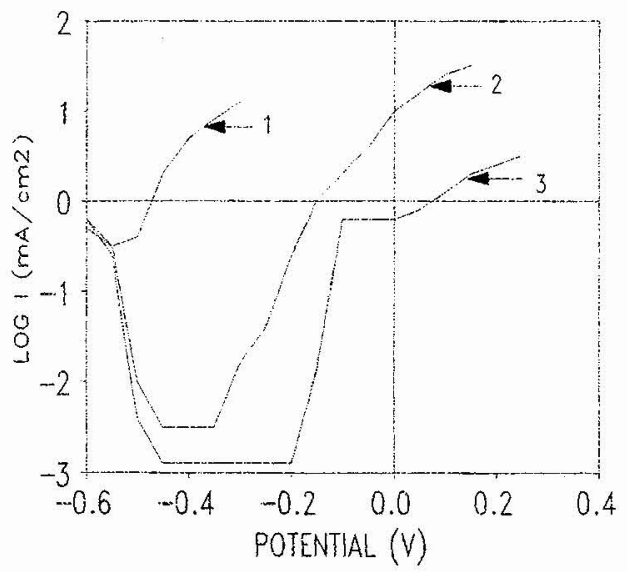

b)

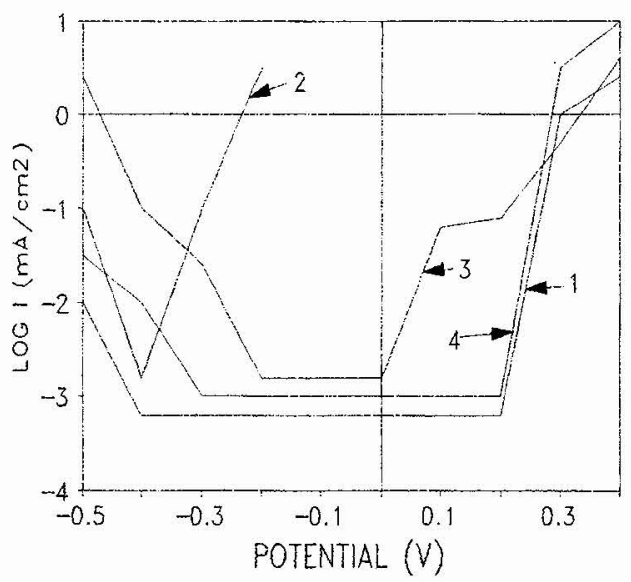

Figure 3. Anodic polarization curves measured in a $0.5 \mathrm{M} \mathrm{NaCl}$ aqueous solution for:

a) Armco iron (1), Ti(OCN) layer (2), composite nitrided + Ti(OCN) layer (3) on Armco iron

b) $1 \mathrm{H} 18 \mathrm{~N} 9 \mathrm{~T}$ steel (1), nitrided layer (2), composite nitrided + Ti(OCN) layer (3), composite nitrided + TiN layer (4) on $1 \mathrm{H} 18 \mathrm{~N} 9 \mathrm{~T}$ steel. 
Figure 4 shows the resistance to frictional wear of the surface layers formed on $1 \mathrm{H} 18 \mathrm{~N} 9 \mathrm{~T}$ and SW7M steels.

a)
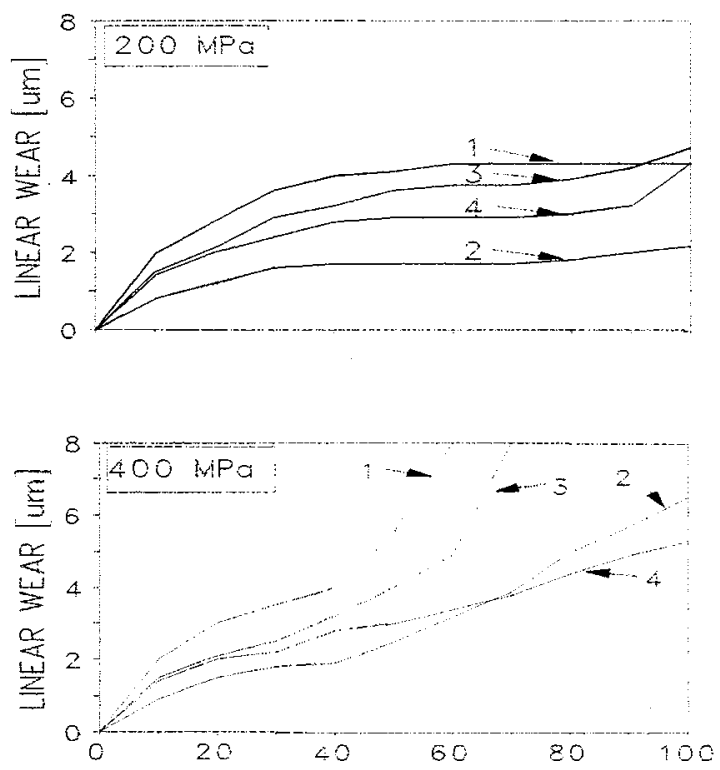

b)
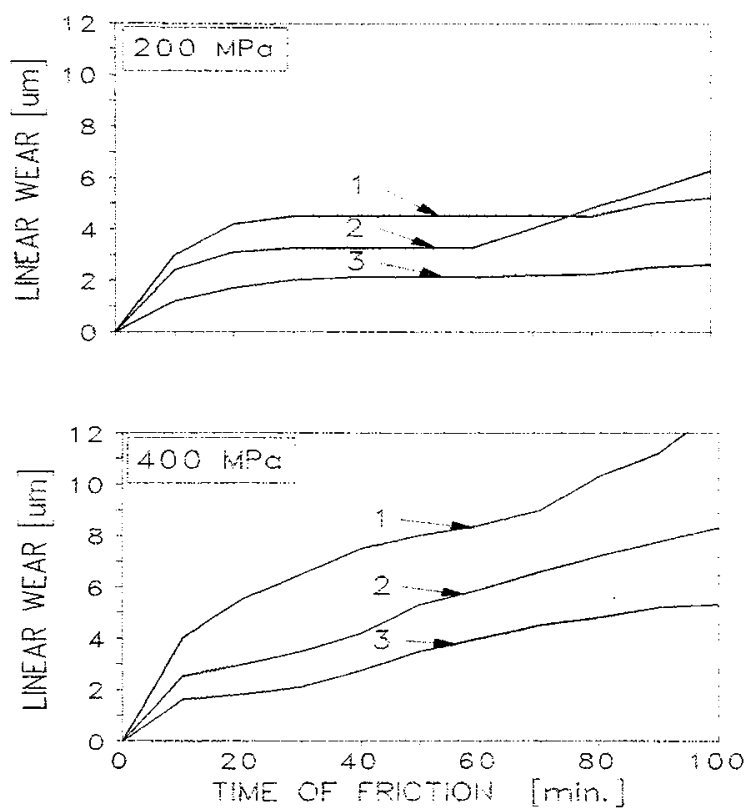

Figure 4. Linear wear occuring on a) 1 H I8N9T steel: a nitrided layer (1), a composite nitrided + TiN layer (2), a Ti(OCN) layer (3), and a nitrided + Ti(OCN) layer (4); and b) on SW7M steel: a Ti(OCN) layer (1), a composite nitrided + Ti(OCN) layer (2), a composite nitrided + TiN layer (3) as a function of friction time at unit loads 200 and $400 \mathrm{MPa}$. 
Our investigation have shown that the composite layers of the nitrided + TiN or nitrided $+\mathrm{Ti}(\mathrm{OCN})$ layer type produced on both Armco iron and stainless or high-speed steel guarantee an increase of the corrosion resistance (Fig. 3) and the frictional wear resistance (Fig. 4). It is known that the corrosion resistance of surface TiN layers depends on their porosity and structural defects $[8,9]$, and that the nitriding of the stainless steel lowers markedly its corrosion resistance. The increased corrosion resistance of the composite layers can be explained by the fact that factors such as the temperature and chemical composition of the gaseous atmosphere, the electrical activation of the gaseous medium, the highly developed surface zone of the nitrided layer and the structural deffects produced in it by cathode sputtering, and also the possibility of producing a nitrided layer without a compounds zone, permit us to control the microstructure and chemical composition and thereby the corrossion properties of the $\mathrm{TiN}$ or $\mathrm{Ti}(\mathrm{OCN})$ layers produced. When analysing the anodic polarization curves we can see that the composite layers of the nitrided $+\mathrm{Ti}(\mathrm{OCN})$ type produced for example on Armco iron increase the corrosion potential from about $-600 \mathrm{mV}$ in the case of uncovered (without a surface layer) Armco iron or from $-350 \mathrm{mV}$ for a $\mathrm{Ti}(\mathrm{OCN})$ layer to $-200 \mathrm{mV}$ obtained for composite layers of the nitrided $+\operatorname{Ti}(\mathrm{OCN})$ type. Moreover, we can see that the layers have undergone passivation. This guarantees a improvement of the corrosion resistance. The nitriding process applied to stainless steel worsens its resistance to corrosion (the corrosion potential is $-500 \mathrm{mV}$ ), whereas the deposition of, for example, a surface TiN layer on prenitrided steel decidedly improves the corrosion resistance of the composite layer thus obtained so that is not worse than that of stainless steel. This is due to the very fine-grained structure of the titanium nitride produced. The results of the examination of the resistance to frictional wear have shown that a nitrided layer increases this resistance since it provides a sufficiently hard support for the Ti(OCN) or TiN layer. We can see from Fig. 4a that by producing composite layers of the nitrided + $\mathrm{Ti}(\mathrm{OCN})$ or nitrided + TiN type (diffusion nitrided layers deposited for example on stainless steel have a thickness in the range 60 to $120 \mu \mathrm{m}$ depend on the conditions of prenitriding process and a hardness about $1200 \mathrm{HV0.05)}$ we can markedly increase the wear resistance even, though the hardness of the core material (stainless steel) is low. This is best observed when the wear examinations are carried out at high unit loads (400 MPa.), at which the stainless steel specimens covered with a nitrided layer or with a Ti(OCN) layer alone undergo seizure (Fig. 4a).

\section{FINAL REMARKS}

The multicomponent layers of the Ti(OCN) type and the composite layers of the nitrided + TiN or $\mathrm{Ti}(\mathrm{OCN})$ layer type show a good resistance to corrosion and to frictional wear. Under glow discharge conditions, these layers can be produced at a temperature between 500 and $550^{\circ} \mathrm{C}$. Prenitriding of the steel substrate increases the resistance to corrosion and to frictional wear, so that the layers may be used for practical purposes. An important advantage of the process lies in that the atmosphere does not contain chlorine.

\section{References}

1. K.T. Rie, A. Gebauer, Materials Science and Engineering, A 139, (1991), 61.

2. H.R. Stock, H. Berndt, P. Mayr, Surface and Coatings Technology, 46, (1991), 15.

3. T. Wierzchon, J. Michalski, J. Rudnicki, B. Kulakowska, W. Zyrnicki, Journal of Material Science, 27, (1992), 771 .

4. T. Wierzchon, J.R. Sobiecki, Vaccum, 44, (10), (1993), 975.

5. T Sadahiro, S. Tamaya, K. Shibuki, N. Ujie, Wear, 8, (1978), 291.

6. J. R. Sobiecki, T. Wierzchon, accepted for publication for X Euro CVD.

7. Polish Standard PN-83/H-D4302. The strenght test of metals. The friction test in the 3-rollerscone system.

8. B. Matthes, E. Broszeit, J. Aroma [at al], Surface and Coatings Technology 49, (1992), 489.

9. J.H. Penttinen, A.S. Korhonen, E. Hajn, [at al], Surface and Coatings Technology 50 (1992), 161. 